\title{
Propostas para a educação científica com base em estudos de história da física na primeira metade do século KK em uma abordagem transnacional
}

\author{
Proposals for science education based on studies of \\ history of physics in the first half of the zDth century \\ in a transnational approach
}

\begin{abstract}
Alexandre Bagdonas
Doutor em Ensino de Ciências

Universidade Federal de Lavras

alebagdonas@gmail.com
\end{abstract}

Recebido em: 13/01/2020

Aceito em: 29/04/2020
Resumo

Apresentamos estudos sobre a história da física na primeira metade século XX, em especial sobre cosmologia e física nuclear, a partir das trajetórias científicas de George Gamow, Robert Oppenheimer e Gleb Wataghin, que foram base a criação de propostas didáticas que visam contribuir para a educação científica em uma perspectiva que valoriza discussões sobre ciência, tecnologia e sociedade. Para isso, selecionamos historiadores que adotaram uma abordagem transnacional da história da ciência, que enfatiza a circulação de cientistas e saberes no período entre guerras, dando atenção a como as complexas identidades nacionais dos cientistas influenciaram suas trajetórias científicas.

Palavras-chave: história transnacional; jogos; história da física; cosmologia; física nuclear

\section{Abstract}

We present studies about history of physics in the first half of the 20th century, in particular about cosmology and nuclear physics, from the scientific trajectories of George Gamow, Robert Oppenheimer e Gleb Wataghin, which allowed the creation of didactic proposals whose goal is to contribute to science education in an approach that values discussions about science, technology and society. For this, we selected historians who adopted a transnational approach to history of science, that highlights the circulation of scientists and knowledge in the interwar period, with focus on how the scientists' complex national identities influenced their scientific trajectories.

Keywords: transnational history, games; history of physics; cosmology; nuclear physics 


\title{
Introdução
}

Este trabalho tem como objetivo contribuir para a aproximação entre estudos de história da ciência, visando à criação de propostas didáticas para o ensino de física na educação básica. Há uma longa tradição de autores que defendem que esta aproximação é importante (ZANETIC, 1989; MATHEWS, 1994). O estudo apropriado de casos históricos pode, por exemplo:

\begin{abstract}
promover compreensões sobre as dificuldades inerentes ao desenvolvimento científico; a criação de novas abordagens ao longo do desenvolvimento da ciência; o papel da observação e do experimento na produção de novos conhecimentos; o papel da descoberta acidental; as condições nas quais ideias são modificadas ou substituídas; o papel do conhecimento prévio na realização, planejamento e controle de experiências; a relação entre ciência e tecnologia; o caráter dinâmico da ciência; o papel da comunidade científica; e a relação entre ciência e sociedade (ROZENTALSKI, 2018, p.23).
\end{abstract}

Em particular, temos nos dedicado ao estudo de casos históricos que permitem integrar essa abordagem histórico-filosófica para contribuir com a abordagem da educação CTSA (ciência, tecnologia, sociedade e ambiente). Esta abordagem tem como pontos principais [a] proporcionar aos alunos subsídios para que pensem criticamente problemas socioambientais, [b] promover visões mais complexas sobre a chamada "natureza da ciência", além de [c] preparar os jovens para a cidadania, nos debates de uma sociedade democrática (STRIEDER, 2012).

Erminia Pedretti e Joanne Nazir (2011) apresentam seis vertentes para esta abordagem educacional: 1) aplicação dos conhecimentos científicos e tecnológicos na resolução de problemas sociais do cotidiano; 2) o aspecto histórico e sociocultural da ciência;3) raciocínio lógico e argumentação; 4) de valores e debates envolvendo ética na ciência; 5) aspectos socioculturais e multiculturalismo e 6) justiça socioambiental e ativismo (CONRADO, 2017).

Temos nos dedicado principalmente com a segunda vertente, mas sempre buscando articular as discussões às outras dimensões da educação CTSA. Esta abordagem se refere à história da ciência como uma dimensão essencial da educação CTSA, como forma de discutir o crescimento e mudança da ciência e tecnologia em associação com as sociedades em que estão inseridas, seu papel e influência e demandas cada vez maiores (ZIMAN, 1994; PEDRETTI e NAZIR 2011). Temos estudado casos históricos relacionados à física no século XX que permitem a elaboração e investigação de atividades didáticas na educação básica e/ ou ensino superior, problematizando as condições de produção da ciência, enfocando questões relacionadas à política, economia, cultura, religião e outros fatores "externos" que influenciem a dinâmica interna da ciência (BAGDONAS 2019). Espera-se, como desdobramento, que tais discussões históricas permitam o desenvolvimento de visões mais críticas sobre o funcionamento da ciência, permitindo, assim, apropriações menos ingênuas do conhecimento científico e, portanto, a possibilidade de participação crítica em decisões envolvendo ciência, tecnologia e ambiente em nossa sociedade atual.

Neste artigo, vamos apresentar propostas didáticas que temos desenvolvido, baseadas em estudos de história da física no século XX, com ênfase na circulação de cientistas e conhecimentos, evidenciando aspectos regionais e culturais da prática científica. Para isso, estudamos abordagens transnacionais da história da ciência neste período. Esta abordagem histórica é já bem estabelecida no âmbito da história, e envolve tirar o foco dos estados-nação como unidade de análise, e, ao invés disso, enfatizar as relações complexas entre pessoas e lugares, cruzando diferentes países. Principalmente no século XX, com o crescimento da comunidade científica e sua mobilidade, esta abordagem historiográfica, ainda que não muito comum, é cada vez mais necessária para entender com profundidas os processos científicos (KRIGE, 2019).

John M. Ziman, físico neozelandês que fez importantes estudos envolvendo a relação entre ciência e sociedade, e também sobre sua importância para a educação (ZIMAN, 1994), analisou os dilemas envolvidos na circulação de cientistas (ZIMAN, 1977). Defendeu a importância de congressos como forma de cientistas 
de diferentes nacionalidades interagirem e trocarem experiências. Por outro lado, também analisou casos em que cientistas viajaram para o exterior, mas com tempos de visita muito curtos para poderem assimilar algo relevante antes de voltar para seus países de origem. Com o crescimento da comunidade científica, e com uma procura cada vez maior de conferências, que ficam com um público em excesso e deixa pouca margem para trocas efetivas, de forma que a maioria dos cientistas volta para casa da mesma maneira que estava antes de iniciar a viagem.

Ziman também analisou eventos na história do século XX, como as duas guerras mundiais e a ascensão de regimes ditatoriais, que levaram a inibição da circulação internacional de cientistas momentaneamente. Um exemplo de limitação da circulação de cientistas ocorreu na Primeira Guerra Mundial. Após o chamado "manifesto dos 93", em que cientistas alemães assinaram um documento se posicionando em defesa do exército alemão, acusado de ter usado armas químicas e cometer atrocidades na invasão da Bélgica, muitos acadêmicos ingleses, franceses e dos EUA aderiram a um boicote contra a ciência alemã. Albert Einstein, um pacifista e crítico do nacionalismo alemão, se recusou a assinar. No final do conflito, países neutros, como Suécia, Noruega e Dinamarca, mantiveram contato tanto com cientistas dos países Aliados quanto com alemães (KEVLES, 1971; BAGDONAS, 2015).

Ao longo da década de 1930, centenas de físicos judeus, muitos dos quais eram os principais especialistas em física até então, emigraram da Europa para os EUA (WEINER, 1969). Alguns destes deles estabeleceram importantes centros de pesquisa e tiveram carreiras promissoras. Entretanto, era comum que sentissem falta de seu país de origem, sentindo-se desajustados na nova cultura. Diferentemente, alguns cientistas evitavam viajar, pois "ideias devem ter origens antes que possam viajar. Para ter novas ideias, talvez o melhor seja ficar em casa e pensar” (ZIMAN, 1977, p. 93). Niels Bohr, um dos principais físicos do século XX, seria um exemplo da afirmação de Ziman de duas formas. Por um lado, ele se beneficiou por estar em um país neutro no período entreguerras, recebendo dezenas de jovens físicos talentosos neste período conturbado, quando havia inibição do contato entre cientistas alemães com seus rivais na guerra: ingleses, franceses e estadunidenses. Bohr esteve em Copenhague por quase toda sua vida, realizando poucas viagens para interagir com Rutherford, em Cambridge, na Inglaterra.

Nas próximas seções, vamos apresentar como esta abordagem histórica que enfatiza o aspecto social da ciência, e o trânsito de cientistas na primeira metade do século XX têm sido empregada na construção de propostas didáticas que visam promover o ensino de ciências contextualizado, mostrando a ciência como construção humana, permeada por questões sociais, políticas e culturais. Iniciaremos apresentando o Jogo Cosmic, desenvolvido em 2012, para o ensino de história da cosmologia no período entreguerras. Em seguida, abordamos como estudos sobre o trânsito de cientistas no mesmo período tem embasado propostas para o ensino de história da física na primeira metade do século XX, levando a uma visão mais rica da ciência. Abordamos brevemente aspectos destes estudos nas trajetórias de Robert Oppenheimer, Werner Heisenberg, Niels Bohr, George Gamow e Gleb Wataghin conjugando-os a trabalhos em história da física nuclear.

\section{Jogo COSMIC}

O COSMIC é um jogo criado por professores de física interessados em abordagens de História e Filosofia da Ciência (HFC) e CTSA no ensino de ciências, que enfatiza a dimensão geográfica da produção científica no período entreguerras. Este jogo teve como objetivo inicial o ensino de cosmologia no ensino médio e foi produzido coletivamente por diversos membros do grupo de pesquisa TeHCo, no Instituto de Física da Universidade de São Paulo. ${ }^{1}$ O Cosmic começou a ser desenvolvido em maio de 2012, por professores de física, muitos dos quais eram pós-graduandos do Programa Interunidades em Ensino de Ciências. Ele foi usado pela primeira vez em experimentos didáticos realizados na Escola Estadual Ana Rosa de Araújo, em São Paulo, entre abril e junho de 2013, em aulas no ensino médio (BAGDONAS, 2015).

1 http://portal.if.usp.br/tehco/pt-br/node/328 acesso em janeiro de 2020. 
Neste RPG (role playing game), os alunos atuam como investidores de uma instituição de fomento fictícia, mas inspirada em eventos históricos, a subdivisão de Cosmologia da Fundação Rockefeller. Para isso, pesquisam informações sobre possíveis cientistas que têm desenvolvido pesquisas promissoras viajando para diferentes países. Ao longo das aulas, o tempo histórico no jogo vai passando, e novos acontecimentos são conhecidos por meio da leitura sobre aspectos políticos, culturais e científicos em cada período.

O material do jogo consiste basicamente de fichas, impressas em cartões de plástico, que contêm fotos, desenhos e textos sobre acontecimentos políticos. Ele foi preparado a partir do estudo de fontes primárias e secundárias sobre a história da ciência na primeira metade do século $\mathrm{XX}^{2}$.

O tabuleiro do jogo é um mapa mundial com conexão entre os países, permitindo viagens para coletar informações a fim de elaborar argumentos sobre quais países devem receber financiamento científico.

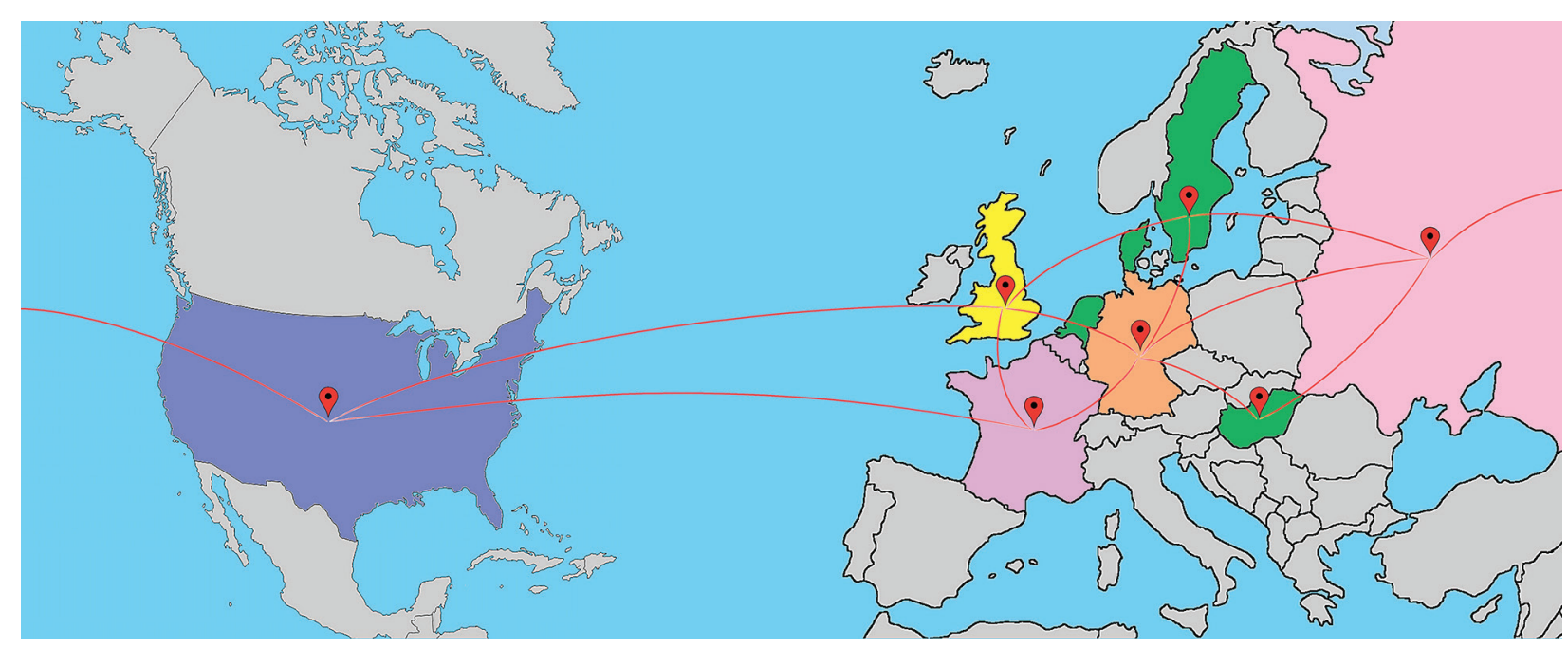

Figural : Mapa do Jogo COSMIC ${ }^{3}$

Após a coleta de informações nas viagens, os investigadores treinam habilidades de escrita e expressão oral, discutindo com a classe e o professor, que atua como presidente da Fundação, quais foram os melhores argumentos formulados. Esta etapa finaliza o primeiro momento pedagógico do jogo, pensado como uma problematização inicial (DELIZOICOV et al., 2002).

Em seguida, em um segundo momento pedagógico, a organização do conhecimento, o professor elege os principais conceitos necessários para o aprofundamento do entendimento sobre modelos cosmológicos e sua relação com episódios históricos. Com isso, busca-se sempre problematizar visões ingênuas de ciência, como a de que ela é neutra e produzida por gênios excêntricos, isolados da sociedade em uma espécie de "torre de marfim".

Finalmente, no terceiro momento pedagógico, a aplicação do conhecimento, investigadores devem fazer uso do que aprenderam na etapa anterior para formular novos argumentos no jogo didático, agora escolhendo um cientista para receber o "Prêmio da rodada". Há uma indicação de um cientista por país, fornecida pelo professor, que sistematiza o que foi discutido nas aulas anteriores.

2 A lista completa das fontes consultadas para a construção das fichas está em (BAGDONAS, 2015, p. 266).

3 O material do jogo está disponível em http://lite.dex.ufla.br/pibidfisica/index.php/cosmic/ O tabuleiro do jogo foi inspirado no tabuleiro do jogo War. 

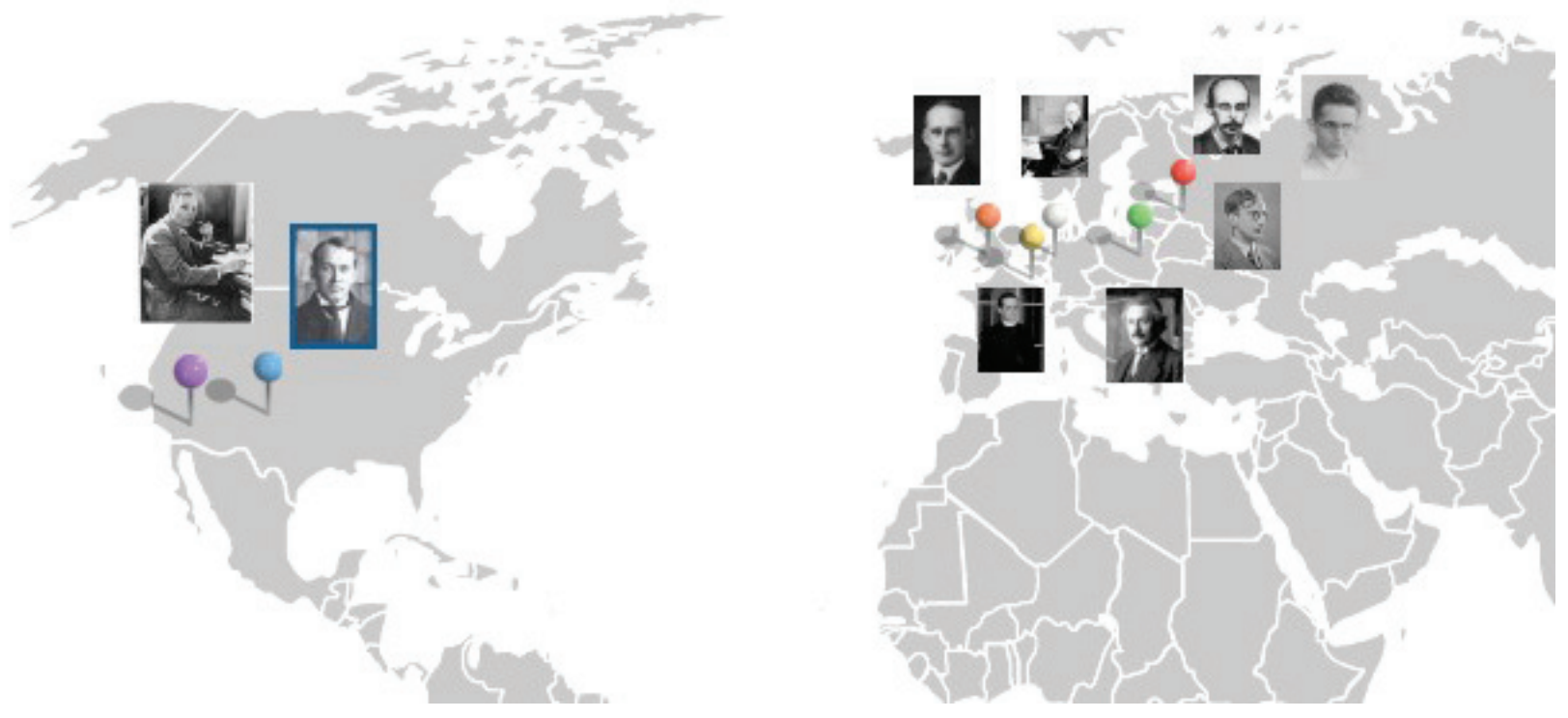

Figura 2 : Mapa Mundi com cientistas indicados para receber financiamento

O mecanismo básico do jogo é simples, sendo facilmente adaptado para o ensino de outros episódios históricos, bastando para isso que sejam produzidas novas fichas. As fichas que criamos para o COSMIC privilegiavam assuntos como história da cosmologia, em particular sobre os modelos cosmológicos estático e em expansão, as tensões entre Alemanha, Inglaterra e Rússia na Primeira Guerra Mundial, com uso de destaque para relações entre ciência e política no período entreguerras. Para isso, empregamos estudos com abordagem mais internalista, com foco nos modelos de universo desenvolvidos na primeira metade do século e nas observações astronômicas que deram suporte a estes modelos, além de obras de historiadores que combinam o estudo dos conceitos com discussões sobre a relação entre política e ciência neste período (BAGDONAS, 2015; BAGDONAS et al. 2018).

Desde então, novos estudos históricos vem sendo desenvolvidos na Universidade Federal de Lavras ${ }^{4}$, como forma de criar propostas didáticas para o ensino de outros conceitos físicos além de cosmologia, como física nuclear, relatividade geral e mecânica quântica (BAGDONAS, 2019). Além disso, buscamos empregar sempre que possível uma variedade de estratégias didáticas para o ensino de história da ciência, como o uso de narrativas (SCHIFFER E GUERRA, 2019), o uso de abordagens lúdicas e de jogos diferentes, como o RPG sobre Máquinas Térmicas, contextualizado pelo ambiente de trabalho na Revolução Industrial (SABKA, 2011). Usamos também personagens e episódios históricos que permitem conduzir discussões interessantes sobre as relações entre ciência, tecnologia e sociedade, em particular sobre física nuclear e suas aplicações militares na guerra, assim como destacar o papel de mulheres na história da ciência, e dar destaque para a ciência nacional.

\section{História da Física Nuclear}

A história da física nuclear, e sua relação com a produção de armas, sem dúvida, é um dos episódios históricos da física do século XX com mais potencial para integrar discussões didáticas envolvendo história e filosofia da ciência e relações entre ciência, tecnologia e sociedade (SORPRESO e ALMEIDA, 2008; LEMOS, 2019; BAGDONAS; 2019). Pensando nas vertentes da educação CTSA, este é um episódio histórico que

4 Neste artigo enfatizamos o que tem sido produzido na Universidade Federal de Lavras, mas como estamos em um projeto de colaboração com outros grupos de pesquisa com interesses semelhantes, boa parte das propostas futuras devem ser feitas colaborativamente. Nossa proposta contribuiu no projeto "Educar para transformar: modelos de ensino para a formação de agentes virtuosos", aprovado no Edital Universal do CNPq (Chamada Universal MCTIC/CNPq n.o 28/2018). 
permite a inserção de debates envolvendo física e sociedade, atravessados por questões éticas. Além de novos jogos didáticos, temos empregado estudos históricos visando incentivar os estudantes em suas construções de narrativas históricas, conjugadas a discussões sobre a natureza da ciência, como forma de fomentar o aprendizado sobre as ciências (MATTHEWS, 1994; BAGDONAS et al. 2018) nas aulas de física.

Em particular, nos interessamos ${ }^{5}$ pela história do desenvolvimento de armas nucleares na Segunda Guerra Mundial. Nossos estudos enfatizaram o desenvolvimento da Física Nuclear, na Alemanha, onde trabalhava Werner Heisenberg, e nos EUA, com foco no Projeto Manhattan, liderado por Robert Oppenheimer. Também teve um papel central neste episódio Niels Bohr, que residia num país inicialmente neutro na Primeira Guerra, o que, como já mencionado, lhe fora favorável para estabelecer sua reputação científica. Porém, após a ocupação nazista da Dinamarca, Bohr passou a cooperar secretamente com os aliados, em suas pesquisas para a produção de armas contra a Alemanha nazista (BAGDONAS, 2019).

Heisenberg e Bohr eram muito próximos e mantiveram colaboração intensa antes da Guerra. Suas discussões foram importantes na criação do Princípio da Incerteza e da Complementaridade. Porém, quando o exército nazista invadiu a Dinamarca, a interação entre eles se tornou tensa, repleta de segredos, gerando especulações sobre os possíveis motivos de seus encontros. Heisenberg continuou na Alemanha e trabalhou no projeto nuclear Alemão, enquanto Bohr, mesmo numa nação ocupada pelo exército nazista, manteve colaboração secreta com cientistas aliados, de forma que, eventualmente, ele podia ter informações sobre a produção de armas nucleares nos EUA. Uma das principais fontes de estudo foi a peça Copenhague de Michael Frayn, que mistura história da ciência e ficção ao imaginar uma conversa fictícia entre Heisenberg, Bohr e sua esposa Margrethe (SILVEIRA et al., 2011; CARDOSO, 2015). Outras fontes importantes foram biografias dos personagens citados e documentários (HEILBRON, 1986; CASSIDY, 2009; GALISON et al. 2018; CARSON e HOLLINGER 2005).

Além de ensinar conceitos básicos de física nuclear, como fissão e fusão nuclear, buscamos também destacar aspectos da circulação dos cientistas durante as décadas de 1920 a 1950, que levaram a criação da mecânica quântica, de sua aplicação para entender a física nuclear e sua aplicação na construção de bombas na Segunda Guerra Mundial. Na construção dos textos didáticos (fichas como as do jogo COSMIC, ou narrativas), além de caracterizar a biografia e principais obras dos personagens centrais da história da física nuclear do século XX, como Albert Einstein, Niels Bohr e Werner Heisenberg, demos destaque a circulação dos cientistas importantes, entretanto, menos conhecidos, como Robert Oppenheimer, George Gamow e Gleb Wataghin.

Julius Robert Oppenheimer (1904 - 1967) foi um físico estadunidense, que iniciou seus estudos em química e física em Harvard (EUA). Já George Gamow (1904-1968) nasceu em Odessa, e estudou física em Leningrado, enquanto Gleb Wataghin (1899-1986) nasceu em Birsula, e estudou física em Turim ${ }^{6}$. Mesmo tendo iniciado suas carreiras em locais distintos, no período entreguerras eles frequentaram os principais grupos de pesquisa europeus que se dedicavam ao estudo de física nuclear.

Os três estiveram em Cambridge, em Londres, visitando o laboratório de Cavendish, liderado pelo físico neozelandês Ernest Rutherford, que após ter recebido o prêmio Nobel em 1908, tornou-se um dos mais respeitados físicos experimentais do mundo, por seus estudos envolvendo modelos atômicos. Oppenheimer esteve em Cambridge em 1924 e 1925; Gamow em 1928 e Wataghin em 1933. Lá acontecia o chamado Kapitza Club, uma reunião de seminários informais, organizado pelo físico russo Piotr Kapitza. Wataghin lembrou da identificação que nutriu por Kapitza pelo fato da origem russa comum, por jogarem xadrez e por terem posições semelhantes em relação à política na URSS, já que tinham simpatia pelo socialismo, mas tinham ressalvas em relação à violência

5 Estes estudos históricos foram realizados por alunos da Universidade de Lavras, orientados pelo autor deste artigo. Entre eles estão a aluna de mestrado profissional Samantha (LEMOS, 2019), e os alunos de iniciação científica Vanderson Santos, que estudou Heisenberg e o projeto nuclear alemão, e Johnnie Pereira, que estudou Oppenheimer e o Projeto Manhattan. Vários outros alunos do nosso grupo de pesquisa também contribuíram na criação de propostas didáticas baseadas nestes estudos (LOPES et al. 2019).

6 Odessa e Birsula ficam atualmente na Ucrânia, mas no início do século XX eram parte do Império Russo. Gamow e Wataghin viveram sua infância num período turbulento na região, nos anos que antecederam a Revolução Russa. 
Assisti a uma explosão de glória, de entusiasmo pela Revolução. E eu mesmo, que me considerava socialista, era muito a favor da Revolução, pessoalmente. De forma que algumas violências me perturbaram. Não eram necessárias, porque a grande massa da população é a favor da revolução. Mas é muito difícil julgar e avaliar os movimentos de grandes massas. Claro. (WATAGHIN, 1975, p. 5)

Entre 1929 e 1932, quando as viagens para fora da URSS eram permitidas, muitos jovens russos, como George Gamow e Lev Landau, estiveram com Kapitza em Londres nestes seminários (KOJEVNIKOV, 2004, p.104). Oppenheimer, Gamow, Wataghin destacaram a importância desta viagem em suas carreiras, contribuindo para sua formação científica, mas tiveram mais interesse por física teórica do que por física experimental, na continuidade de seus estudos. Os três estiveram também visitando Niels Bohr, em Copenhague. Bohr também esteve em Cambridge com Rutherford, mas na década anterior, quando o físico dinamarquês foi laureado com o Nobel, em 1922, por seus estudos envolvendo a estrutura dos átomos e formou um dos principais centros de física teórica do mundo. Como a Dinamarca se manteve neutra na Primeira Guerra, Bohr pode continuar recebendo tanto jovens ingleses, como Paul Dirac, quanto alemães, como Werner Heisenberg, que viriam a se tornar os mais renomados físicos teóricos do século XX, por suas contribuições para o estudo da mecânica quântica.

No final da década de 1920, muitos jovens físicos estavam entusiasmados pelas novidades desta área de pesquisa, como o Princípio da Incerteza, publicado por Heisenberg aos 26 anos, e a mecânica ondulatória de Erwin Schrödinger. Além disso, também apreciavam o clima informal e bem humorado destes encontros. Além de jogos como tênis de mesa e xadrez, gostavam de escalar montanhas e assistir, enquanto discutiam os avanços recentes em física teórica (TAVARES et al., 2020). Por outro lado, é notável que se tratava de um ambiente extremamente competitivo. Wataghin ressaltou a importância de ter se relacionado com físicos renomados em Copenhague, mas que todos, com exceção de Bohr, foram extremamente críticos em relação às apresentações de seus trabalhos envolvendo o comprimento mínimo na mecânica quântica:

Cheguei em Copenhagen, e, pela primeira vez, encontrei Niels Bohr. Tinha o Heitler, Heisenberg, Pauli. Bohr me convidou para expor minhas idéias. Pauli foi presidente da reunião, Chairman. Todos foram muito contra as minhas idéias, porque eu, naquela época, estava pensando que devia ter uma produção múltipla em raios cósmicos. Eu estava estudando raios cósmicos muito, porque era a única coisa que podíamos fazer na Itália. A única pessoa, que, naquela época, me confortou foi Niels Bohr, que, depois da reunião, quando eu estava sozinho, me convidou e disse: "Olha, Wataghin, não fique tão desesperado por estas críticas. - Eles diziam: "You are dreaming, that's wrong", and so on. Eu penso que somente não estamos preparados”. Porque a relatividade estava baseada, naquela época, noconceito de coincidentes num ponto de espaço de Minkowski de quatro dimensões, ponto-tempo. Que era contrário a pequenas regiões (WATAGHIN, 1975, p.7).

Paul Dirac, comentando as escolhas de carreira dos jovens físicos na década de 1920, lembrou que "pessoas que não eram muito boas podiam fazer trabalhos importantes", quando a mecânica quântica estava em sua "era dourada" nos anos vinte. Já no final dos anos 30, com todos os problemas interessantes já resolvidos, "pessoas que eram muito boas já não podiam mais encontrar problemas para resolver" e tinham que mudar para outras áreas de pesquisa (Dirac citado em HOYLE, 1994, p.106). Outro centro importante, que não ficou tão famoso quanto Copenhague, mas que marcou a carreira de muitos físicos teóricos desta geração, foi Göttingen, na Alemanha. Lá, trabalhou físico teórico alemão Max Born e seu jovem assistente Werner Heisenberg. Além dos já citados Gamow e Oppenheimer, estiveram lá Pascual Jordan, Wolfgang Pauli, Paul Dirac, Enrico Fermi e Edward Teller.

Enquanto esteve em Göttingen, Gamow fez sua primeira grande contribuição para a física teórica. Após ler um artigo de Rutherford sobre o decaimento alfa, Gamow percebeu que poderia empregar a recém-desenvolvida mecânica ondulatória de Schrödinger para explicar como partículas alfa, formadas por dois prótons 
e dois nêutrons, podiam escapar do núcleo atômico, num processo que hoje é conhecido como tunelamento quântico (HUFBAUER, 2009). Animado com este ambiente efervescente de discussões envolvendo a física nuclear, ele conseguiu uma bolsa para ficar mais um ano fora da URSS, para interagir com Niels Bohr em Copenhague. Nos anos seguintes, conseguiu uma série de bolsas que o permitiram viajar entre Cambridge, Göttingen e Copenhague, participar de conferências internacionais com curtos períodos de volta a URSS. Gamow ficou um total de 22 meses na Europa Ocidental, entre 1929 e 1931. Com isso, cada vez mais ele se identificou como um físico quântico transnacional, um membro quintessencial da comunidade internacional que tinha Bohr como um pai (BAGDONAS E KOJEVNIKOV, no prelo).

Oppenheimer fez seu doutoramento na Universidade de Göttingen, entre 1926 e 1927. Regressou aos Estados Unidos para dar aulas de física na Universidade de Berkeley e no Instituto de Tecnologia da Califórnia. Ao longo da década de 1930, com a ascensão de Hitler ao poder, diversos cientistas europeus, que como Oppenheimer também participaram das discussões sobre mecânica quântica e física nuclear em Göttingen e Copenhague, imigraram para os EUA, que até então era marcada pelo domínio de físicos experimentais (WEINER, 1969), e fortaleceram a pesquisa em física teórica do país. Enquanto isso, na URSS, o fechamento do regime tornou cada vez mais difícil a realização de viagens internacionais para cientistas soviéticos. Gamow conseguiu liberação do governo soviético para ir à Conferência de Solvay, na Bélgica, onde Bohr, Heisenberg, Marie Curie e outros cientistas importantes discutiram sobre a estrutura e propriedades do núcleo atômico. Após a conferência, Gamow decidiu não voltar mais para a URSS (HUFBAUER, 2009).

Gleb Wataghin emigrou para o Brasil em 1934, onde ficou por 15 anos, e fez contribuições importantes para a física brasileira. Auxiliou jovens estudantes, como Mário Schenberg, Marcello Damy de Souza Santos e Paulus Pompeia, a viajarem por importantes centros de física teórica no exterior, interagindo com físicos renomados, como Enrico Fermi, Paul Dirac, George Gamow e Chandrasekhar. Adotando uma abordagem transnacional, Tavares e colaboradores (2020), argumentam que a circulação de Wataghin através de diferentes culturas durante os anos de seu desenvolvimento profissional foram cruciais na formação de uma identidade científica transnacional:

Os anos de Gleb Wataghin em São Paulo nos dão base para argumentar que, apesar da importância de agências de fomento, entidades governamentais, laboratórios nacionais, universidades e outras entidades, nenhuma delas poderia funcionar sem a presença dos próprios cientistas: os vetores mais eficientes do transnacionalismo na ciência (TAVARES et al., 2020, no prelo).

Alguns dos imigrantes Europeus que saíram da Europa na década de 1930 e foram trabalhar nos EUA foram George Gamow, Edward Teller, Hans Bethe e Enrico Fermi. Já estava claro que ao estudar o núcleo atômico, abriam-se novas possibilidades para obtenção de energia, e novas aplicações, como entender a fonte de energia das estrelas e a possibilidade de produção de armas, já que o clima de "paz armada" após a Primeira Guerra Mundial era evidente. Em 1935, muitos deles se reuniram na I Washington Conference of Theoretical Physics, organizada por Gamow e Teller, para discutir física nuclear. A conferência foi um sucesso. Nos anos seguintes, as discussões seguiram, e cientistas ilustres que continuavam na Europa, como Bohr, participaram dos eventos. Em 1939, a Washington Conference of Theoretical Physics foi dedicada a discutir física de baixas temperaturas. Assim como Wataghin, Gamow e Teller tinham como modelo para suas conferências e encontros aqueles que eles frequentaram quando jovens, em grandes centros de pesquisa em física na Europa, como Cambridge, Göttingen e Copenhague (BAGDONAS e KOJEVNIKOV, no prelo).

Na conferência de Washington de 1939, Niels Bohr fez uma declaração que deixou todos chocados. Anunciou que os físicos Otto Hanh e Fritz Strassmann haviam descoberto a fissão nuclear ao bombardear átomos de urânio projetando nêutrons, produzindo o elemento bário. Imediatamente, os cientistas nos EUA intensificaram as pesquisas em física nuclear, tendo em vista o começo da Segunda Guerra Mundial e a possibilidade de produzir armas. Até mesmo Einstein, um pacifista, que era então pesquisador em Princeton, foi persuadido a usar seu capital simbólico para convencer o presidente dos EUA a investir nesta área de 
pesquisa (GALISON et al., 2018). Oppenheimer acabou sendo convidado para liderar o Projeto Manhattan, que era a concretização do investimento em física nuclear com fins militares. Também participaram físicos nucleares como Hans Bethe e Edward Teller. Inicialmente, a justificativa dos que trabalharam no Projeto era, principalmente, a necessidade de produzir fissão nuclear controlada para fins militares antes que os alemães o fizessem. Com a explosão das bombas atômicas sobre Hiroshima e Nagasaki e o início da Guerra Fria, o temor de uma guerra nuclear que poderia destruir toda a humanidade marcou a visão pública sobre a ciência. Após a rendição da Alemanha, Oppenheimer teve uma grave crise de consciência por ter sido um dos "pais da bomba" (CARSON e HOLLINGER, 2005). A partir de então surgiram visões críticas ao uso da ciência na produção de armas, ao mesmo tempo em que estudos de história, filosofia e sociologia da ciência levaram a um aumento do questionamento da autoridade da ciência.

\section{Considerações finais}

Se na visão positivista a ciência seria confiável por se basear em métodos empíricos, sem espaço para influências políticas, econômicas ou culturais, a partir da segunda metade do século XX se fortaleceu a visão da ciência como uma construção humana, e a neutralidade científica foi fortemente questionada. Por isso, a história da física nuclear, particularmente, quando estudada através de um viés social - que enfatiza a circulação dos saberes e a dimensão política da ciência - tem grande potencial educacional por fomentar discussões envolvendo os valores e a ética científicas além das relações promovidas pelas ciências pura e aplicada (BAGDONAS, 2019).

Desde que foi produzido, o jogo COSMIC gera um incômodo por explicitar que ao invés de utilizar todo o mapa mundi, nosso jogo deixa explícita a concentração de investimento e interesse em países da Europa e EUA. Além disso, os indicados ao prêmio são todos homens e brancos, o que fortalece estereótipos sobre onde e por quem a ciência é produzida. Nesse sentido, tanto na UFLA quanto com colaboradores de outras universidades, pretendemos desenvolver outras propostas didáticas, incluindo jogos baseados em estudos de história da física do século XX que enfatizem a dimensão social e cultural da ciência (SCHIFFER e GUERRA, 2019), dando espaço para discutir a ciência nacional, o caso de Wataghin e o crescimento da física no Brasil (TAVARES et al., 2020), além de estudos envolvendo história da relatividade geral e as observações de eclipses realizadas no Brasil , pelo Grupo TeHCo, na USP (DOMINGOS et al. 2019).

Como perspectivas futuras, pretendemos investigar a viabilidade de pensar estas inovações didáticas em aulas da Licenciatura em Física na Universidade de Lavras, nas disciplinas de História da Física e Ciência, Tecnologia e Sociedade. Futuramente, a ideia seria preparar materiais voltados para o uso em aulas do ensino médio.

\section{Referências}

BAGDONAS, Alexandre. Controvérsias envolvendo a natureza da ciência em sequências didáticas sobre cosmologia. Tese (Doutorado em Ensino de Física) - Ensino de Ciências (Física, Química e Biologia), Universidade de São Paulo, São Paulo, 2015.

BAGDONAS, Alexandre. História da Física para o Ensino de Física como Cultura: Debates sobre a Neutralidade da Ciência no Periodo Entreguerras. In: MARTINS, André Ferrer Pinto (org.). Física, Cultura e Ensino de Ciências. São Paulo: Livraria da Física, 2019. Cap. 8. p. 195-214.

BAGDONAS, Alexandre; ZANETIC, João; GURGEL, Ivã. O maior erro de Einstein? Debatendo o papel dos erros na ciência através de um jogo didático sobre cosmologia. Caderno Brasileiro de Ensino de Física, v. 35, n.1, p. 97-117, 2018.

BAGDONAS, Alexandre; KOJEVNIKOV, Alexei. Funny origins of Big Bang Theory, Historical Studies of Natural Sciences, no prelo. 
CONRADO, Dalia. M. Questões Sociocientíficas na Educação CTSA: contribuições de um modelo teórico para o letramento científico crítico. 2017. 237p. Tese (Doutorado em Ensino, Filosofia e História das Ciências), Instituto de Física, UFBA/ UEFS, Bahia, 2017.

CARDOSO, L. F. M. Versão brasileira da peça de teatro Copenhagen (de Michael Frayn) para fins didáticos, Revista Hipótese, Itapetininga, v. 1, n.1, p. 109-174, 2015.

CARSON, Cathryn; HOLLINGER, David. (Eds.) Reappraising Oppenheimer, Centennial Studies and Reflections, Office for History of Science and Technology, Berkeley, University of California, 2005,413pp.

CASSIDY, D. C. Beyond uncertainty: Heisenberg, quantum physics, and the bomb. New York: Bellevue Literary Press, 2009.

DOMINGOS, Fernando; CARDOSO, Danilo ; LIMA, Nathan ; BAGDONAS, Alexandre . Estudos sobre a história da Relatividade Geral visando a criação de jogos didáticos. In: I Encontro de História da Física, 2019, São Paulo. Atas do I Encontro de História da Física, 2019.

GALISON, Peter L.; HOLTON, Gerald; SCHWEBER, Silvan S. (Ed.). Einstein for the 21st century: His legacy in science, art, and modern culture. Princeton University Press, 2018.

GOMES, André ; PEREIRA, Johnnie ; LEMOS, Samantha ; SANTOS, Vanderson ; BAGDONAS, Alexandre . Desenvolvimento de um jogo didático baseado em estudos da história das armas nucleares. In: I Encontro de História da Física, 2019, São Paulo. Atas do I Encontro de História da Física, 2019.

KOJEVNIKOV, Alexei. Stalin's great science: the times and adventures of Soviet physicists. London: Imperial College Press, 2004.

KRIGE, John. How Knowledge Moves, Chicago: The University of Chicago Press, 2019.

HEILBRON, J. L. The Dilemmas of an Upright Man: Max Planck as Spokesman for German Science, Berkeley: Univ. California Press, 1986

HOYLE, Fred. Home is where the Wind Blows: Chapters from a Cosmologist's Life. (Mill Valley, CA: University Science Books, 1994), p. 106.

HUFBAUER, Karl. “George Gamow, March 4, 1904 - August 19, 1968," Biographical Memoirs of the Fellows of the National Academy of Sciences (2009): 1-39, on 3.

KEVLES, Daniel J. Into Hostile Political Camps: The Reorganization of International Science in World War I.” Isis, v. 62, n. 1, p.47-60, 1971.

LEMOS, Samantha. Contribuições de um texto teatral histórico para o estudo da física nuclear no ensino médio. Lavras: Mestrado Profissional Nacional em Ensino de Física, Universidade Federal de Lavras, 2019. Dissertação de Mestrado em Ensino de Física.

MATTHEWS, Michael. R. Science Teaching: The role of History and Philosophy of Science. Routledge: London, 1994.

PEDRETTI, E.; NAZIR, J. Currents in STSE Education: Mapping a Complex Field, 40 Years On. Science Education, v. 95, p.601-626, 2011.

ROZENTALSKI, Evandro Fortes. Indo além da Natureza da Ciência: o filosofar sobre a Química por meio da ética química. 2018. Tese (Doutorado em Ensino de Química) - Ensino de Ciências (Física, Química e Biologia), Universidade de São Paulo, São Paulo, 2018.

SABKA, Diego Ricardo. Uma abordagem CTS das máquinas térmicas na revolução industrial utilizando o RPG como recurso didático. Dissertação (Mestrado em Ensino de Física) - Universidade Federal do Rio Grande do Sul. Instituto de Física. Programa de Pós-Graduação em Ensino de Física. 2016.

SCHIFFER, Herman; GUERRA, Andreia. Problematizando Práticas Científicas em Aulas de Física: o uso de uma História Interrompida para se Discutir Ciência de Forma Epistemológica-Contextual. Revista Brasileira de Pesquisa em Educação Em Ciências, 19, 95-127, 2019.

SILVEIRA, Alessandro Frederico; RIBEIRO FILHO, Aurino; SILVA, Ana Paula Bispo. Os princípios de complementaridade e de incerteza na obra Copenhague de Michael Frayn: a arte e a teoria quântica. In:FREIRE JR, O., PESSOA JR, O., and BROMBERG, JL., orgs. Teoria Quântica: estudos históricos e implicações culturais [online]. Campina Grande: EDUEPB; São Paulo: Livraria da Física, 2011. 456 p. ISBN 978-85-7879-060-8.

SORPRESO, Thirza Pavan; ALMEIDA, Maria José. Discursos de licenciandos em física sobre a questão nuclear no ensino médio: foco na abordagem histórica. Ciência \& Educação (Bauru), v. 16, n. 1, p. 37-60, 2010. 
STRIEDER, Roseline. Abordagens CTS na educação científica no Brasil: sentidos e perspectivas. 2012. 283f. Tese (Doutorado) - Programa Interunidades em Ensino de Ciências, Faculdade de Educação, Instituto de Física, Instituto de Química, Instituto de Biologia/Universidade de São Paulo, São Paulo, 2012.

TAVARES, Heráclio; BAGDONAS, Alexandre; VIDEIRA, Antonio. Transnationalism as Scientific Identity: Gleb Wataghin and Brazilian Physics, 1934-1949, Historical Studies of Natural Sciences, v. 50, no. 3, p. 248-301, 2020.

ZIMAN, John. The rationale for STS is in the approach. In J. Solomon \& G. Aikenhead (Eds.), STS education: International perspectives on reform (pp. 21 - 31). New York: Teachers College Press, 2014.

ZIMAN, John., “The International Scientific Community: ideas move around inside people," Minerva, 15, no. 1, p. 83-93, 1977.

WATAGHIN, Gleb. Gleb Wataghin (depoimento, 1975). Rio de Janeiro, CPDOC, 2010. 45 p.

WEINER, Charles. "A New Site for the Seminar: the Refugees and American Physics in the Thirties" in The Intellectual Migration: Europe and America, 1930-1960, ed. Donald Fleming and Bernard Bailyn, Cambridge; Harvard University Press, 190-234, 1969.

ZANETIC, João. Física também é cultura. Tese de Doutorado. Faculdade de Educação, Universidade de São Paulo, 1989. 